\title{
Agreement between the clinical pulmonary infection score and NHSN criteria for surveillance of ventilator associated pneumonia
}

\author{
Nasia Safdar', John C. O'Horo' ${ }^{2}$, Rosa Mak ${ }^{3}$, Josh Medow ${ }^{1}$ \\ 1. University of Wisconsin School of Medicine and Public Health, Wisconsin, USA \\ 2. Mayo Clinic, Wisconsin, USA \\ 3. University of Wisconsin Hospitals and Clinics, Wisconsin, USA
}

doi: 10.3396/ijic.v9i1.008.13

\begin{abstract}
This study evaluated the utility of the original and modified Clinical Pulmonary Infection Score (CPIS) compared with the National Healthcare Safety Network (NHSN) surveillance definition of VAP. The kappa statistic was 0.81 when comparing original CPIS and NHSN and 0.39 when comparing modified CPIS and NHSN. The CPIS score has good correlation with NHSN criteria but does not offer a major advantage over NHSN criteria for VAP surveillance. Further research is essential to identify an optimal reference standard for VAP surveillance.
\end{abstract}

\section{Key words}

Pneumonia, ventilator-associated; Severity of illness index; antibacterial agents and therapeutic use.

\section{Background}

Ventilator associated pneumonia (VAP) impacts 10$20 \%$ of patients requiring mechanical ventilation and nearly doubles the risk for mortality in critically ill patients. ${ }^{1}$ Prevention of VAP is hampered by challenges in the definitions and diagnosis. In particular, surveillance definitions for VAP are especially problematic, because of inter-observer variability and lack of specificity and sensitivity. ${ }^{2}$
There is no gold standard for surveillance of VAP, but the most widely used method is the Centers for Disease Control (CDC) National Healthcare Safety Network (NHSN) algorithm ${ }^{4}$ by which to make a clinical/microbiologic diagnosis of VAP (Table I). These criteria are prone to inter-observer variability, especially a clinical diagnosis category of VAP which does not require microbiologic confirmation of the diagnosis. ${ }^{5}$ Better methods for surveillance of VAP

\section{Corresponding Author}

Dr. Nasia Safdar

MFCB 5221 University of Wisconsin Hospital and Clinics,

Madison, WI 53705; Wisconsin, USA

email: ns2@medicine.wisc.edu 
are needed. The Clinical Pulmonary Infection Score (CPIS, table I) was proposed in 1991 as a diagnostic method for VAP and has also been studied as a tool for reducing unnecessary antibiotic use in critically ill patients. ${ }^{6}$ The CPIS relies in part on microbiologic data that are usually not immediately available, and a modified CPIS was developed which only includes data immediately available on patient presentation. ${ }^{7,8}$ The CPIS has limitations but the score is easy to calculate and may play a role in VAP surveillance. ${ }^{5}$ The objective of this study was to evaluate the degree of agreement between the CPIS and modified CPIS and the NHSN surveillance definitions of VAP.

\section{Methods}

\section{Setting}

The University of Wisconsin Hospital is a 536-bed, acute care tertiary referral hospital, with five Intensive Care Units (ICUs). Surveillance for VAP is performed in all the ICUs year round by an experienced infection preventionist, with input from the hospital epidemiologist. Current standard of care for VAP prevention includes use of the ventilator bundle, with head of bed elevation to at least 30 degrees, oral care with chlorhexidine twice daily and stress ulcer prophylaxis.

Subjects were identified in the University of Wisconsin Hospital adult multidisciplinary ICU and neurosurgical ICU using the respiratory therapy department's daily list of mechanically ventilated patients. This was conducted as standard infection control activities and approved by the hospital infection control committee. Inclusion criteria for initiating surveillance were mechanical ventilation and clinical suspicion of pneumonia based on fever and presence of a new infiltrate on chest radiography. Exclusion criteria included diagnosis of pneumonia prior to ventilation, suspected incubating pneumonia at time of intubation or not requiring mechanical ventilator support.

Patients meeting inclusion criteria were identified daily, and data extracted from the electronic medical record, including respiratory therapy notes describing respiratory secretions quantity and colour, was used to determine CPIS and NHSN VAP scores. Data was collected from March-September 2009 and January and February 2010. There was a three month interruption with no surveillance performed between Oct 2009-
Dec 2009 due to lack of personnel resources during the beginning of the $2009 \mathrm{H} 1 \mathrm{~N} 1$ pandemic.

The Centers for Disease Control National Healthcare Safety Network (CDC NHSN) definition for pneumonia and the $\mathrm{CPIS}^{6}$ and modified $\mathrm{CPIS}^{9}$ scoring systems are described in table I. ${ }^{4}$ The maximum score for the CPIS is 12 and for the modified CPIS score is 10 . A CPIS $>6$ was considered positive for VAP for both the original and modified CPIS score. ${ }^{8}$

The correlation between the two systems was measured using Cohen's Kappa statistic ( $\kappa) . \kappa$ is a robust tool for measuring observational correlation, taking into account the variation due to chance. Standard error for $\kappa$ was calculated using the original equation proposed by Cohen. ${ }^{10} \mathrm{~A} \kappa$ of $<0.20$ shows poor agreement, 0.21-0.40 fair, 0.31-0.60 moderate, 0.61-0.80 good and 0.81-1.00 very good agreement. The sensitivity, specificity and likelihood ratios were calculated for both the CPIS and modified CPIS scoring systems using the NHSN definition as a gold standard.

\section{Results}

A total of 73 ventilated patients were identified as meeting the inclusion criteria during the study period. Of these, 36 met CDC criteria for VAP, 35 were highlikelihood VAP by original CPIS and 14 were high likelihood by modified CPIS. This is summarized in table II. Original CPIS showed a high degree of concordance with the CDC criteria with a Cohen's $\kappa$ of $0.81(95 \%$ $\mathrm{Cl}$ 0.67-0.94). Modified CPIS showed only a fair to moderate concordance at $\mathrm{k}=0.39(95 \% \mathrm{Cl}$ 0.22-0.56). Patients who met CDC criteria had a mean CPIS score of $7.9(95 \% \mathrm{Cl}=4.9-10.9)$ and a mean modified CPIS score of $6.3(95 \% \mathrm{Cl}=3.3-9.3)$. In patients not meeting CDC criteria for VAP, mean original CPIS was 4.1 (95\% $\mathrm{Cl}=0.9-7.3)$ and modified CPIS $2.9(95 \% \mathrm{Cl}=0-6.9)$.

Treating the CDC criteria as the reference standard, the original CPIS has a sensitivity of $0.89(95 \% \mathrm{Cl} 0.73-$ $0.96)$ and a specificity of $0.91(95 \% \mathrm{Cl} 0.77-0.97)$. Positive likelihood ratio is $10.96(95 \% \mathrm{Cl}=3.68-32.64)$ and negative likelihood ratio is $0.12(95 \% \mathrm{Cl}=0.05-$ 0.31). When using modified CPIS, sensitivity is 0.39 (95\% Cl 0.24-0.56), specificity 1.0 (95\% Cl=0.881), positive likelihood ratio cannot be defined, and negative likelihood ratio is $0.61(95 \% \mathrm{Cl} 0.47-0.79)$. 


\section{Discussion}

In this study, we explored whether the use of a CPIS or modified CPIS may be of utility for the surveillance of VAP. The original CPIS had a high concordance with the CDC NHSN criteria for surveillance of VAP. Microbiologic data was vital to making a correct diagnosis of VAP, as the omission of this information in the modified CPIS decreased the k significantly. To our knowledge, this is the first study to compare the CPIS score with the NHSN criteria for surveillance of VAP. Since the initial description in 1991, the CPIS score and the subsequently modified CPIS have been studied in a number of settings for their role in the diagnosis of VAP with varying results. A recent meta-analysis

Table I. Criteria for diagnosing VAP CDC/NHNS (top) and Clinical Pulmonary Infection Score ${ }^{6}$ and modified CPIS. ${ }^{7}$ criteria for VAP in adults. For the CDC criteria, to fit the criteria for VAP, patient must be on ventilator or extubated $<48$ hours, and meet criteria described in table. Different criteria for identifying VAP exist for immunocompromised patients, and can be found in the CDC NHNS publication ${ }^{4}$ Clinical Pulmonary Infection Score ${ }^{6}$ and modified CPIS. ${ }^{7}$ Total score of $>6$ suggests VAP.

\begin{tabular}{l} 
Radiology \\
\hline Two or more serial chest x ray showing \\
at least one of the following \\
- New or progressive and persistent \\
infiltrate \\
- Consolidation \\
- Cavitation
\end{tabular}

One $X$ ray is acceptable if the patient has no underlying cardiac or pulmonary disease

\section{Signs/Symptoms/Laboratory}

At least one of the following:

- Fever (>38 C) not attributable to other cause

- Leukopenia $\left(<4000 \mathrm{WBC} / \mathrm{mm}^{3}\right)$ or leukocytosis $(>12,000$ $\mathrm{WBC} / \mathrm{mm}^{3}$ )

- Altered mental status without recognized cause in adults $>69$ years old

AND at least two of the following

- New onset of purulent sputum, increased or otherwise changed respiratory secretions or increased suctioning requirements

- Worsening cough, dyspnea or tachypnea

- Rales or bronchial breath sounds

- Worsening gas exchange evidenced by changes in saturations, blood gas, oxygen requirement or ventilator demand

\begin{tabular}{l|r|r|r|r}
\hline Sign & $\mathbf{0}$ & $\mathbf{1}$ & $\mathbf{2}$ & Modified Scoring \\
\hline Temperature, ${ }^{\circ} \mathrm{C}$ & $36.5-38.4$ & $38.5-38.9$ & $<36$ or $>39$ & \\
\hline $\begin{array}{l}\text { White blood cell } \\
\text { count }\left(\text { cells } / \mathrm{mm}^{3}\right)\end{array}$ & $4.0-11.0$ & $<4$ or $>11$ & $>50 \%$ band forms & \\
\hline $\begin{array}{l}\text { Oxygenation } \\
\mathrm{paO}_{2} \text { :Fio2 }\end{array}$ & $>240$ or ARDS & $\ldots$ & $<240$ and no ARDS & \\
\hline $\begin{array}{l}\text { Chest radiograph } \\
\text { findings }\end{array}$ & No infiltrate & $\begin{array}{r}\text { Diffuse (or patchy) } \\
\text { infiltrates }\end{array}$ & Localized infiltrate & \\
\hline $\begin{array}{l}\text { Tracheal secretions } \\
\text { score }\end{array}$ & $<14$ & $>14$ & Purulent & \\
\hline $\begin{array}{l}\text { Culture of tracheal } \\
\text { aspirate }\end{array}$ & $\begin{array}{r}\text { Pacteria cultured } \\
\text { minimal or no } \\
\text { growth }\end{array}$ & $\begin{array}{r}\text { bacteria cultured } \\
\text { moderate or more } \\
\text { growth }\end{array}$ & $\begin{array}{r}\text { Moderate of greater } \\
\text { growth of pathogenic } \\
\text { bacteria same as on } \\
\text { original Gram stain }\end{array}$ & Not included \\
\hline
\end{tabular}


Table II. VAP by CDC and CPIS scores. Original CPIS scores on top, modified version below. $\mathrm{k}=\mathbf{0 . 8 1}$ with original CPIS, $\mathrm{k}=0.39$ with modified version.

CDC vs. CPIS (original version)

\begin{tabular}{lcrrr}
\hline \multirow{2}{*}{ VAP per CPIS } & VAP per CDC & TOTAL \\
\cline { 2 - 4 } & NO & YES & TO \\
\hline LOW Likelihood $(\leq 6)$ & 34 & 4 & 37 \\
HIGH Likelihood $(>6)$ & 3 & 32 & 35 \\
\hline TOTAL & 37 & 36 & 73 \\
\hline
\end{tabular}

CDC vs. CPIS (modified version)

\begin{tabular}{lcccr}
\hline \multirow{2}{*}{ VAP per CPIS } & VAP per CDC & \multirow{2}{*}{ TOTAL } \\
\cline { 2 - 4 } & NO & YES & \\
\hline LOW Likelihood $(\leq 6)$ & 37 & 22 & 59 \\
HIGH Likelihood $(>6)$ & 0 & 14 & 14 \\
\hline TOTAL & 37 & 36 & 73 \\
\hline
\end{tabular}

of CPIS with quantitative microbiologic analysis of VAP included thirteen studies and found pooled estimates for sensitivity and specificity for CPIS to be $65 \%(95 \% \mathrm{Cl} 61-69 \%)$ and $64 \%(95 \% \mathrm{Cl} 60-67 \%)$, respectively. ${ }^{11}$ However, the analysis did not focus on surveillance definitions for VAP. Our results extend the current literature in this field by comparing the NHSN surveillance definition for VAP with CPIS and modified CPIS. Although the modified CPIS had only a moderate correlation with the NHSN definition, the original CPIS had good concordance. The original score includes microbiologic culture information thus may have limited utility for rapid diagnosis of VAP; however, it may still be of value for surveillance where this diagnosis does not have to be made as promptly as for patient care.

Several studies have alluded to the limitation of the CPIS score. ${ }^{5,12}$ In particular, the utility of CPIS has been shown to vary greatly by patient population. In trauma patients, CPIS cannot reliably distinguish between VAP and non-infectious trauma related systemic inflammatory response syndrome. ${ }^{13}$ In burn patients, a retrospective study noted that CPIS performed poorly in predicting VAP in this patient population. ${ }^{14}$

Our study had several limitations. Our population had an extremely high pre-test probability of VAP, with approximately half of all study patients meeting NHSN criteria for VAP. Thus, our results may not be generalised to populations with a low pre-test probability of VAP. Moreover, our study had a small sample size, and thus we were not able to perform subgroup analyses to examine the performance of CPIS in differing populations. Finally, there was a gap in surveillance during a three-month period in 2009 which may also have impacted our results.

Our results support the contention that better diagnostic and surveillance methods for VAP are needed. This is an area of active inquiry ${ }^{15}$ and recent research has identified objective criteria that may be more useful than the current NHSN definition. ${ }^{16}$ The new, proposed surveillance definition algorithm for ventilator-associated events (VAE), which includes but is not limited to ventilator-associated pneumonia is anticipated to be implemented in NHSN in 2013. As a surveillance definition, it is not intended for use in the clinical management of patients. Ventilator-associated events are identified by using a combination of objective criteria: deterioration in respiratory status after a period of stability or improvement on the ventilator, evidence of infection or inflammation, and laboratory evidence of respiratory infection. These offer significant advantages over the current methods of surveillance. Moreover, unlike in the current NHSN 
definition, patients must be mechanically ventilated for more than 2 calendar days to be eligible for VAE, which is more in keeping with the pathogenesis of VAP. Research to examine clinical and process outcomes using this new surveillance definition is ongoing.

In conclusion, we found that CPIS did not confer a major advantage over the current NHSN definition for surveillance of VAP. Future studies should examine assessment of alternative VAP surveillance methods, including the new proposed surveillance algorithm from NHSN.

\section{References}

1. Safdar N, Dezfulian C, Collard HR, Saint S. Clinical and economic consequences of ventilator-associated pneumonia: a systematic review. Critical care medicine 2005; 33: 21842193. http://dx.doi.org/10.1097/01.CCM.0000181731.53912. D9

2. Webb SA, Pettila V, Seppelt I, et al. Critical care services and 2009 H1N1 influenza in Australia and New Zealand. N Engl J Med 2009; 361: 1925-1934. http://dx.doi.org/10.1056/ NEJMoa0908481

3. Klompas M. Does this patient have ventilator-associated pneumonia? JAMA 2007; 297: 1583-1593. http://dx.doi. org/10.1001/jama.297.14.1583

4. CDC. Ventilator associated pneumonia (VAP) events. In: CDC, ed. Device associated events. Atlanta, GA: CDC; 2011: 6-1: 6-14.

5. Thorburn K, Darbyshire A. Death by acid rain: VAP or EXIT? Critical care 2009; 13: 1008. http://dx.doi.org/10.1186/cc8169

6. Pugin J, Auckenthaler R, Mili N, Janssens JP, Lew PD, Suter PM. Diagnosis of ventilator-associated pneumonia by bacteriologic analysis of bronchoscopic and nonbronchoscopic "blind" bronchoalveolar lavage fluid. The American review of respiratory disease 1991; 143: 1121-1129.
7. Singh N, Rogers P, Atwood CW, Wagener MM, Yu VL. Shortcourse empiric antibiotic therapy for patients with pulmonary infiltrates in the intensive care unit. A proposed solution for indiscriminate antibiotic prescription. American journal of respiratory and critical care medicine 2000; 162: 505-511.

8. Fartoukh M, Maitre B, Honore S, Cerf C, Zahar JR, Brun-Buisson C. Diagnosing pneumonia during mechanical ventilation: the clinical pulmonary infection score revisited. Am / Respir Crit Care Med 2003; 168: 173-179. http://dx.doi.org/10.1164/ rccm.200212-1449OC

9. Rosbolt MB, Sterling ES, Fahy BG. The utility of the clinical pulmonary infection score. Journal of intensive care medicine 2009; 24: 26-34. http://dx.doi. org $/ 10.1177 / 0885066608327097$

10. Cohen J. A coefficient of agreement for nominal scales. Educational and Psychological Measurement 1960; 20: 37-46. http://dx.doi.org/10.1177/001316446002000104

11. Shan J, Chen HL, Zhu JH. Diagnostic accuracy of clinical pulmonary infection score for ventilator-associated pneumonia: a meta-analysis. Respir Care 2011; 56: 1087 1094. http://dx.doi.org/10.4187/respcare.01097

12. Zilberberg MD, Shorr AF. Ventilator-associated pneumonia: the clinical pulmonary infection score as a surrogate for diagnostics and outcome. Clin Infect Dis 2010; 51 Suppl 1: S131-135. http://dx.doi.org/10.1086/653062

13. Croce MA, Swanson JM, Magnotti LJ, et al. The futility of the clinical pulmonary infection score in trauma patients. I Trauma 2006; 60: 523-527; discussion 527-528. http://dx.doi. org/10.1097/01.ta.0000204033.78125.1b

14. Pham TN, Neff MJ, Simmons JM, Gibran NS, Heimbach DM, Klein MB. The clinical pulmonary infection score poorly predicts pneumonia in patients with burns. J Burn Care Res 2007; 28: 76-79. http://dx.doi.org/10.1097/BCR.0b013E31802C88DB

15. Improving surveillance for ventilator associated events in adults: overview and proposed new definition algorithm. In: Prevention CfDCa, ed. Atlanta, GA: National Center for Emerging and Zoonotic Infectious Diseases/Division of Healthcare Quality Promotion; 2012.

16. Klompas M, Khan Y, Kleinman K, et al. Multicenter evaluation of a novel surveillance paradigm for complications of mechanical ventilation. PLoS One 6: e18062. http://dx.doi. org/10.1371/journal.pone.0018062 